\title{
BASES CONCEITUAIS EM CLIMATOLOGIA GEOGRÁFICA
}

\author{
Profa. Dra. Juliana Ramalho Barros \\ Instituto de Estudos Sócio-Ambientais da UFG \\ Campus Samambaia, Caixa Postal 131 - CEP: 74.001-970, Goiânia - GO - Brasil \\ Tel./Fax: (62)3521-1077 -juliana.ufg@superig.com.br \\ Prof. Dr. João Afonso Zavattini \\ zavattini@rc.unesp.br
}

\begin{abstract}
RESUMO
A Climatologia encontra suas bases na Meteorologia, que estuda a atmosfera e seus fenômenos, e preocupa-se com o registro e a medição dos mesmos, a fim de que possa determinar as condições físicas sob as quais foram produzidos. Desta forma, o inevitável confronto entre a Climatologia e a Meteorologia envolve os geógrafos numa discussão - sobre o uso e a aplicação de cada uma delas - que se deve iniciar, essencialmente, pelas definições de "tempo" e "clima". O presente trabalho apresenta uma discussão sobre as bases conceituais da Climatologia e da Meteorologia, apoiando-se nas várias formas de abordagem de cada uma no intuito de apontar metodologias que mais atendam aos propósitos da chamada Climatologia Geográfica.
\end{abstract}

Palavras-chave: Climatologia Geográfica; meteorologia; clima.

\begin{abstract}
The climatology is founded on the Weather, who studies the atmosphere and its phenomena, and is concerned with the registration and measurement of the same, so that it can determine the physical conditions under which they were produced. Thus, the inevitable clash of Climatology and Meteorology geographers involves a discussion - about the use and application of each one of them - is due to start, essentially, the definitions of "time" and "climate". This paper presents a discussion of the conceptual foundations of climatology and meteorology, relying on ways to approach each one in order to highlight methods that attend more to the purpose of calling Geographical Climatology.
\end{abstract}

Keywords: Geographical Climatology; meteorology; climate.

\section{RESUMÉ}

La climatologie a sa base dans la météorologie, qui étudie l'atmosphère et de ses phénomènes, et est préoccupé par l'enregistrement et de mesure de la même manière que peut déterminer les conditions physiques dans lesquelles ils ont été produits. Ainsi, l'inévitable confrontation entre les géographes de climatologie et de météorologie les mets dans un débat - à propos de l'utilisation et l'application de chacun -, il devrait commencer, en substance, les définitions de «temps» et «climat». Cet article présente une analyse de la base conceptuelle de la climatologie et de la météorologie, en s'appuyant sur plusieurs manières d'aborder chacun d'eux afin d'identifier les méthodes pour répondre aux besoins de plusieurs appels de climatologie géographique.

Mots- Clés: Climatologie géographique; météorologie; climat.

\section{Introdução}

A Meteorologia apresenta dois domínios de pesquisa: a Meteorologia Tradicional e a Meteorologia Dinâmica. O primeiro deles estuda os elementos atmosféricos separadamente e, por isto mesmo, também recebe a denominação de Meteorologia Analítico-separativa. Esta forma de abordagem, inicialmente desintegra a realidade atmosférica, pois estuda cada um de seus elementos de forma separada e, só depois, tenta reconstruir, laboriosamente, o complexo vivo (ou atmosférico) que a priori destruíra. Já o segundo, o da Meteorologia Dinâmica considera, em conjunto, todos os estados do meio atmosférico (o tempo e as massas de ar) e, desta forma, é possível afirmar que ele é sintético e atende melhor às necessidades da Geografia, ciência que se interessa mais pelas combinações do que por fatos isolados (PÉDELABORDE, 1970).

Sobre esses dois domínios da Meteorologia, Monteiro (1971, p. 4) chama a atenção para a "necessidade de se analisar atentamente os conceitos básicos a partir da meteorologia que se aceita como válida e dá caráter normativo às pesquisas". 
A Climatologia, um dos ramos da Geografia Física, segundo Pédelaborde (1970, p. 5), estuda “os caracteres da atmosfera em contato com a superfície terrestre e a distribuição espacial desses caracteres". Para isso, relaciona-se com outras áreas da Geografia Física, da Geografia Humana e da Geografia Biológica, uma vez que as características do complexo atmosférico encontram-se diretamente ligadas à existência e à articulação de todas as outras características da superfície terrestre. Entretanto, em função da natureza dos elementos que analisa, a Climatologia encontra suas bases na Meteorologia, que estuda a atmosfera e seus fenômenos, e preocupa-se com o registro e a medição destes, a fim de que possa determinar as condições físicas sob as quais foram produzidos (ZAVATTINI, 2000).

O inevitável confronto entre a Climatologia e a Meteorologia envolve os geógrafos numa discussão - sobre o uso e a aplicação de cada uma delas - que se deve iniciar, essencialmente, pelas definiç̧ões de "tempo" e "clima". O tempo é uma combinação passageira, efêmera, de curta duração. Já o clima é um conjunto de tendências - mais ou menos estáveis - que resulta em condições relativamente permanentes, durante um período de tempo mais extenso, mais longo ou mais duradouro.

Para os meteorologistas o tempo é o "conjunto de valores que, em um dado momento e em um determinado lugar, caracterizam o estado atmosférico" (BALDIT Apud PÉDELABORDE, 1970, p. 9), ou seja, é uma combinação que existe num dado momento, porém no instante seguinte já é outra, diferente da anterior. Desta definição, três idéias podem ser extraídas: a) os elementos do clima não agem isoladamente; $b$ ) as combinações são instantâneas, efềmeras; e, c) tais combinações ocorrem em pontos precisos da superfície da Terra. Como se vê, trata-se de uma noção de tempo muito restritiva, muitíssimo estreita.

Aos geógrafos interessa uma noção mais ampla de tempo, motivo pelo qual a mais apropriada seria a de "tipos de tempo", que é mais abrangente e se refere, justamente, às combinações que se repetem, nem sempre idênticas, porém produtoras de sensações fisiológicas semelhantes, ou, conforme Pédelaborde (1970, p. 10), "quando uma combinação aparece freqüentemente (não exatamente, é claro, mas com os constituintes muito próximos e produzindo efeitos praticamente iguais), ela constitui um tipo de tempo".

A partir dos conceitos de "tempo" e "tipos de tempo" pode-se, então, discutir o que vem a ser o clima, cujo estudo, ao contrário daquele de tempo, requer práticas metódicas e pacientes, para que possa ser compreendido na sua totalidade.

O clima, assim como o tempo, resulta da combinação de elementos, mas, neste caso, trata-se da combinação de tendências "dominantes" e "permanentes" dos elementos mais gerais da atmosfera sobre um lugar (PÉDELABORDE, 1970).

Uma das definições de clima que merece ser examinada é a de Hann (Apud PÉDELABORDE, 1970, p. 19), segundo o qual o clima é "o conjunto de fenômenos meteorológicos que caracterizam o estado médio da atmosfera em um ponto da superfície terrestre".

A definição de Hann, aceita pelos geógrafos durante muito tempo, apresenta uma enorme incompatibilidade com o tipo de estudo do clima capaz de revelar a realidade de forma mais concreta. É que embora recomende o estudo do conjunto de fenômenos em contato com a superfície terrestre, a concepção de Hann encara o clima como sendo uma média, transformando-o numa abstração. Portanto, a noção de tipos de tempo não cabe nesta proposta, que, além do mais, também não leva em conta o desenrolar dos fenômenos no tempo cronológico, sendo, então, inadequada aos propósitos da Geografia.

A outra definição de clima a ser examinada é a de Sorre (1951). Este autor, baseado nos avanços da meteorologia dinâmica, realiza uma revisão do conceito de Hann, mantendo a referência à característica local do complexo climático, mas assumindo uma nova postura no que diz respeito à dinâmica deste complexo. Desta forma, o clima passa a ser definido como "o ambiente atmosférico constituído pela série de estados da atmosfera sobre um lugar em sua sucessão habitual” (SORRE, 1951, p. 14).

O conceito sorreano de clima considera os estados da atmosfera em sua totalidade e não o estado médio, englobando toda a série desses estados, o que significa que não deixa de lado os tipos excepcionais que as médias mascaram completamente. Além disso, este conceito leva em conta a sucessão dos tipos de tempo, ou seja, o seu ritmo e a sua duração, o que o torna apropriado para a Climatologia Geográfica, 
já que o estudo da sucessão dos tipos de tempo permite explicar os mecanismos do clima (PÉDELABORDE, 1970).

Essa breve revisão conceitual tentou deixar claro que a Climatologia está diretamente vinculada à Meteorologia, enquanto que esta, por seu turno, apresenta duas linhas de abordagem: a Meteorologia Tradicional e a Meteorologia Dinâmica. Por conseqüência, a Climatologia, que nelas se apoia, também possui dois métodos para conduzir os seus estudos, cujos nomes são idênticos aos da Meteorologia, ou sinônimos, conforme explicitados a seguir.

\section{A Climatologia Separativa.}

Também conhecida como Climatologia Analítico-separatista (MONTEIRO, 1962), a Climatologia Separativa tem suas bases na Meteorologia Tradicional e apoia-se no conceito que Hann atribuiu ao clima.

No método analítico-separatista cada elemento do clima (temperatura, pressão atmosférica, umidade, precipitações, vento, insolação, nebulosidade, dentre outros) é considerado de forma isolada e, com base nas observações meteorológicas realizadas, calculam-se médias que são utilizadas para a elaboração de cartas e gráficos.

Este método, apesar de amplamente empregado nos estudos do clima de diversas regiões do globo, ao separar os elementos climáticos, isolando-os entre si e transformando-os em médias aritméticas, acaba por dissolver a realidade, que é constituída pelo conjunto de elementos atuantes, uns através dos outros.

Outro problema deste método refere-se aos valores extremos e aos menos ocasionais, que são totalmente mascarados pelo uso das médias aritméticas, que colocam os elementos numa situação de uniformidade que, na verdade, não existe. Por isso, é possível afirmar que o método analítico-separatista não possibilita a visualização do ritmo climático, uma vez que, segundo Monteiro (1962), a sucessão dos valores menos ocasionais é um dos indicadores do ritmo próprio da atmosfera sobre um determinado lugar.

Do ponto de vista geográfico, ainda que tenha sua utilidade, o método tradicional apresenta lacunas, uma vez que é estático, ou seja, não é capaz de restituir o dinamismo aos fenômenos e suas verdadeiras sucessões de estados, o que impossibilita a compreensão fiel da realidade.

Assim, já que a abordagem analítico-separatista, baseada em valores médios, não permite o conhecimento das causas dos fenômenos climáticos, pois destrói a conexão entre eles existente e, também, com os demais elementos da superfície terrestre, cabe à Geografia buscar e adotar novas abordagens para o estudo do clima.

\section{A Climatologia Sintética}

A Climatologia Sintética está diretamente ligada à Meteorologia Dinâmica, que analisa o complexo atmosférico em porções individualizadas, isto é, as massas de ar atuantes, preocupando-se, ainda, com os seus conflitos, ou seja, com os mecanismos frontológicos que elas próprias engendram (MONTEIRO, 1962).

A evolução da Meteorologia Dinâmica e a proposta climática de Sorre (1951) possibilitaram novas formas de abordagem em Climatologia.

É o caso da proposta do "método sintético das massas de ar e dos tipos de tempo", de Pédelaborde (1970), através da qual cada tipo de tempo deve ser analisado a partir de seus elementos constituintes, mas sem extraí-los do conjunto para fazê-los entrar em cálculos que os isolariam dos demais componentes do clima.

O mais importante no estudo da realidade climática é compreender a maneira como o complexo se manifesta, assim como o quadro que ele compõe e a ação fisiológica que ele exerce. Além disso, são também muito significativas as condições que determinam esse complexo: a origem da massa de ar, quanto tempo ela permaneceu sobre um determinado lugar, qual trajetória seguiu, quais propriedades físicas ela 
levou consigo e quais transformações ela sofreu antes de atingir o ponto de observação (PÉDELABORDE, 1970).

Ao estudar os tipos de tempo da Bacia Parisiense, Pédelaborde (1957 Apud ZAVATINI, 1998), embora atento ao conceito de clima preconizado por Sorre (1951), acabou revelando as limitações de sua proposta metodológica, pois "produziu apenas uma descrição sumária e sistemática, um catálogo de tipos de tempo" (ZAVATINI, 1998, p. 10). No entanto, no Brasil, o Professor Carlos Augusto de Figueiredo Monteiro, ao realizar seus estudos de clima, alcançou uma fiel e lúcida tradução do conceito sorreano de clima sem, contudo, deixar de usufruir as vantagens do método sintético das massas de ar e dos tipos de tempo (ZAVATINI, 1998).

A diferença entre a abordagem de Monteiro e aquela de Pédelaborde, refere-se a um paradigma presente na concepção de Sorre (1951). Enquanto para Pédelaborde (1970) o paradigma é "a totalidade dos tipos de tempo", para Monteiro (1976, p. 30), trata-se do "ritmo", quer dizer, do "encadeamento, sucessivo e contínuo, dos estados atmosféricos e suas articulações no sentido de retorno aos mesmos estados", no que se conecta ao pensamento de Sorre (1951, p. 33), segundo o qual o ritmo "exprime não mais a distância quantitativa dos valores sucessivos, mas o retorno mais ou menos regular dos mesmos estados".

Ciente de que adotar o paradigma do ritmo significa utilizar os recursos da Meteorologia Dinâmica, Monteiro apoia-se nos trabalhos dos meteorologistas brasileiros Adalberto Serra e Leandro Ratisbonna, o que lhe possibilitou a formulação dos princípios metodológicos que regeriam a pesquisa em Climatologia Geográfica no Brasil.

No artigo intitulado "Da necessidade de um caráter genético à classificação climática (Algumas considerações metodológicas a propósito do estudo do Brasil meridional)”, publicado no ano de 1962, Monteiro inicia sua caminhada rumo à sistematização dos estudos climáticos à luz do método dinâmico, dando origem à "escola de climatologia geográfica brasileira”.

Se o novo paradigma climático é o ritmo, como chegar a visualizar e compreender o ritmo climático de um determinado lugar?

Monteiro (1962, p. 12) acredita "na necessidade de recorrer à dinâmica atmosférica, não apenas esporadicamente na interpretação de fatos isolados, mas, com a devida ênfase, na própria definição climática regional". É que além de possibilitar a compreensão da gênese dos fenômenos, a análise da circulação atmosférica regional demonstra, ainda, a ineficiência dos valores médios dos elementos do clima, uma vez que os mesmos ocultam justamente o ritmo.

A preocupação com a ação combinada dos diferentes elementos do clima no seu ritmo de sucessão habitual, com a utilização das seqüências de cartas sinóticas do tempo e com a necessidade de aperfeiçoamento da classificação genética dos climas em termos regionais, levaram Monteiro a conceber a técnica batizada de "análise rítmica", que consiste na representação do ritmo climático através de gráficos que são "longas faixas de representação diária concomitante de todos os atributos atmosféricos mensuráveis (e possíveis de obter) sobre um lugar, acompanhados da informação sobre o sistema meteorológico atuante em cada dia" (MONTEIRO, 1976, p. 30).

Desses gráficos diários, cujas possibilidades de representação prática do ritmo são excelentes, Monteiro (1964) extrai os índices de participação das massas de ar e os aplica na classificação climática que, por sua vez, passa a ter uma base genética. Revela-se, então, a importância do caráter regional quando se estuda o clima à luz da metodologia dinâmica.

A análise rítmica é apropriada para a investigação da realidade do clima, na perspectiva geográfica, tanto por suas possibilidades de representação das variações cronológicas dos elementos atmosféricos num dado espaço (ou lugar) como, ainda, pela premissa que encerra, isto é, de que "apenas a partir da escala diária é possível associar a variação dos elementos do clima com os tipos de tempo que se sucedem segundo os mecanismos da circulação regional" (MONTEIRO, 1971, p. 9).

Na prática da análise rítmica em climatologia é conveniente a utilização de anos-padrão (ou períodospadrão), conforme propôs Monteiro (1973), pois são amostras verdadeiras dos diferentes tipos de tempo 
ocorridos sobre um dado local (ou região) e revelam os encadeamentos rítmicos que os diversos sistemas atmosféricos ali engendram. Como em nosso país as características climáticas predominantes são do tipo tropical ou subtropical, é compreensível que a chuva seja o elemento climático com melhor capacidade de traduzir as variações rítmicas presentes num dado ano, ou as que se alternam de um ano para outro, seja ele um ano civil, agrícola, ou relativo a qualquer outra convenção periódica. Explica-se, assim, a preponderância de temas ligados à pluviosidade na maioria dos estudos de climatologia geográfica realizados no Brasil. Porém, como lembra Monteiro (1971), a fim de manter o caráter geográfico da análise, a caracterização de um ano-padrão (ou período-padrão) não pode estar presa somente às informações quantitativas (meros totais anuais ou mensais, por exemplo), devendo também considerar certos critérios qualitativos, especialmente aqueles ligados ao ritmo de sucessão dos estados atmosféricos ou, em outras palavras, à variação diária do tempo meteorológico num ponto da superfície terrestre.

Tendo em vista que Monteiro, ao adotar o conceito sorreano de clima, tanto reconhece a necessidade de mudança do paradigma climático então em vigor como busca dar um caráter verdadeiramente geográfico à Climatologia, o mesmo deveria ser considerado, como bem lembra Zavatini (1998), o responsável pela criação de uma "escola brasileira de climatologia geográfica" ou "escola de climatologia dinâmica brasileira".

\section{A Climatologia Separativa e a Climatologia Sintética: abordagens excludentes ou complementares?}

Com base neste breve apanhado sobre as bases conceituais em Climatologia Geográfica, é possível afirmar que, de maneira geral, a Climatologia Separativa (ou Tradicional) se utiliza de dados reais e os transforma em abstratos, já que os mesmos são convertidos em valores médios e, portanto, tornam-se desprovidos de seu significado real. Já a Climatologia Sintética (ou Dinâmica) procura analisar as variações dos elementos do clima através de dados concretos, preferencialmente diários, na tentativa de alcançar as seqüências rítmicas que explicam tais variações. Assim, a perspectiva da Climatologia Geográfica é dinâmica e parece não haver dúvida que o seu paradigma é o ritmo. Entretanto, a abordagem da Climatologia Dinâmica não exclui a da Climatologia Tradicional.

Por um lado, a abordagem tradicional quantitativa demanda longos períodos de observação e de registro dos fenômenos meteorológicos, ao passo que o tratamento dinâmico qualitativo usa amostras cronológicas do tempo atmosférico que melhor representem a realidade climática (episódios, períodos, "anos-padrão"). Por outro lado, os valores médios de longas séries temporais são capazes de apontar as tendências, as freqüências e as amplitudes dos diversos elementos climáticos no espaço geográfico.

No que se refere à perspectiva espacial, ainda que as médias de longas séries temporais se afastem da realidade, a maior ou menor eficiência dos estudos climáticos executados à luz da metodologia tradicional irá depender, fundamentalmente, da densidade da rede de observações meteorológicas. Somente uma distribuição espacial homogênea de postos e estações possibilitará resultados confiáveis. Já no caso da abordagem dinâmica, Monteiro (1969) lembra que a projeção espacial pode ser alcançada através de análises realizadas ao longo de eixos (ou transetos), desde que os mesmos sejam capazes de refletir os mecanismos "habituais" e "excepcionais" da dinâmica atmosférica regional, mesmo que as observações meteorológicas ao longo desses transetos não apresentem longas séries de dados, embora um número maior de observações sempre aprimore a análise climática.

Porém, a verdadeira compreensão do ritmo climático só será possível se os valores médios forem deixados de lado, para que os extremos sejam visualizados e considerados como parte integrante da realidade climática de um lugar. Por esta razão, o que de fato importa é qual será o tratamento estatístico a ser aplicado aos elementos climáticos observados, coletados e armazenados pela rede meteorológica de uma dada região. Também é importante a maneira pela qual os resultados obtidos serão analisados, pois a retirada de amostras em Climatologia Geográfica vai além de uma mera análise quantitativa. Ela depende, sempre, da capacidade do pesquisador em definir, do ponto de vista rítmico, o que é habitual e o que é excepcional na sua área de estudo. E, tal definição, está diretamente ligada à sucessão dos 
estados atmosféricos, ou seja, ao conceito climático de Sorre (1951).

Uma vasta rede de observatórios meteorológicos, bem distribuída e com dados confiáveis, seria o ideal para um estudo de clima. Entretanto, já que a realidade é bem diferente daquela que seria a ideal, é necessário buscar métodos que sejam capazes de fornecer a maior aproximação possível, mesmo quando as condições de pesquisa são adversas.

O tratamento dinâmico não invalida nem substitui o tradicional, mas representa, sim, um complemento necessário ao aprofundamento dos conhecimentos climatológicos da Terra, uma vez que "as duas técnicas de análise, que devem andar juntas, assumem atitudes diferentes em suas projeções no tempo e no espaço" (MONTEIRO, 1969, p. 14).

\section{Considerações Finais}

Para que os fenômenos atmosféricos fossem plenamente explicados as atenções deveriam estar voltadas para o ritmo, pois ele é a essência do fato climático. Porém, os estudos de uma esfera tão dinâmica como a atmosfera, nem sempre buscaram alcançar o equilíbrio entre a forma tradicional de abordagem (analítico-separativa) e aquela sintética. Afinal, cada um desses dois tratamentos, por mais adequados que possam parecer, sozinhos são incapazes de desvendar, por completo, o quadro climático de um dado espaço geográfico.

É certo que a aplicação de técnicas estatísticas que mascarem o comportamento real dos elementos climáticos deve ser evitada ao máximo. Entretanto, mesmo a abordagem dinâmica utiliza índices de participação das massas de ar e das frentes atuantes sobre diferentes áreas do globo terrestre, com vistas à classificação climática de base genética. E assim fez Monteiro (1973), ao analisar a distribuição das chuvas no Estado de São Paulo, ao longo de diferentes “anos-padrão", representativos do ritmo atmosférico "habitual" e "excepcional" e, por conseqüência, de gênese pluvial também diversas.

Muitos anos mais tarde, Barros (2003) também lançou mão da combinação das duas abordagens metodológicas para descrever e analisar o regime pluviométrico na área do Distrito Federal, bem como explicar episódios de caráter excepcional.

Isso revela que, na verdade, a individualidade climática só pode ser alcançada quando, num mesmo estudo, à representação qualitativa da sucessão dos tipos de tempo (ou encadeamento dos estados atmosféricos) associamos as variações quantitativas dos principais elementos do clima (pressão, umidade, nebulosidade, temperatura, chuva, vento, etc.). Afinal, cada trecho do nosso planeta apresenta uma realidade geográfica própria, motivo pelo qual Monteiro (1971) adverte que a aplicação dessas análises, tanto a qualitativa quanto a quantitativa, deve estar integrada ao espaço regional, e que os parâmetros admitidos como válidos para uma dada área podem não o ser para outra.

Assim, com relação às duas abordagens, aqui enfocadas, pode-se concluir que uma complementa a outra, e que vislumbrar e compreender o verdadeiro quadro climático significa, também, saber equilibrálas nas investigações a que se propõe realizar.

\section{Referência Bibliográfica}

BARROS, J. A chuva no Distrito Federal: o regime e as excepcionalidades do ritmo. 2003. 221 p. (Mestrado em Geografia) - Instituto de Geociências e Ciências Exatas. Universidade Estadual Paulista. Rio Claro.

MONTEIRO, C. A. de F. Da Necessidade de um Caráter Genético à Classificação Climática (Algumas Considerações Metodológicas a Propósito do Estudo do Brasil Meridional). Revista Geográfica. Rio de Janeiro, v. 31, n. 57, p. 29-44, 1962.

MONTEIRO, C. A. de F. Sobre um Índice de Participação das Massas de Ar e suas Possibilidades de Aplicação à Classificação Climática. Revista Geográfica. Rio de Janeiro, v. 33, n. 61, p. 59-69, 1964.

MONTEIRO, C. A. de F. A Frente Polar Atlântica e as Chuvas de Inverno na Fachada Sul-Oriental do Brasil (Contribuição Metodológica à Análise Rítmica dos Tipos de Tempo no Brasil). São 
Paulo: Universidade de São Paulo/Instituto de Geografia, 1969. 68 p. (Série Teses e Monografias nº 1).

MONTEIRO, C. A. de F. Análise Rítmica em Climatologia: problemas da atualidade climática em São Paulo e achegas para um programa de trabalho. São Paulo: Universidade de São Paulo/Instituto de Geografia, 1971.21 p. (Série Climatologia n 1).

MONTEIRO, C. A. de F. A Dinâmica Climática e as Chuvas no Estado de São Paulo - estudo geográfico sob forma de atlas. São Paulo: Universidade de São Paulo/ Instituto de Geografia, 1973. 129 p.

MONTEIRO, C. A. de F. Teoria e Clima Urbano. São Paulo: Universidade de São Paulo/ Instituto de Geografia, 1976. 181 p.(Série Teses e Monografias n² 25).

PÉDELABORDE, P. Introduction à l'étude scientifique du climat. Paris: SEDES, 1970. 246 p.

SORRE, M. Le Climat. In: SORRE, M. Les Fondements de la Géographie Humaine. Paris: Armand Colin, 1951. Chap. 5, p.13-43.

ZAVATINI, J. A. A Climatologia Geográfica Brasileira, o Enfoque e a Noção de Ritmo Climático. Revista Geografia. Rio Claro, v. 23, n. 3, p. 5-24, 1998.

ZAVATTINI, J. A. O Paradigma da Análise Rítmica e a Climatologia Geográfica Brasileira. Revista Geografia, Rio Claro, v. 25, n. 3, p. 25-43, 2000. 